\title{
Hybrid HVDC for Integrating Wind Farms with Special Consideration on Commutation Failure
}

\author{
Rong Zeng, student member, IEEE, Lie Xu, senior member, IEEE, Liangzhong Yao, senior member, \\ IEEE, Stephen J. Finney, and Yi Wang, member, IEEE
}

\begin{abstract}
This paper presents the control and operation of a hybrid HVDC system comprising a wind farm side VSC rectifier and a grid side LCC inverter for integrating wind power. The configuration and operation principle of the hybrid HVDC system are described. Commutation failure in the LCC inverter during an AC network disturbance is considered and its impact on the hybrid system operation is analyzed. An enhanced control strategy for the LCC inverter at the grid side and an alternative MMC topology using mixed half-bridge and full-bridge modules considered for the rectifier at the wind farm side are proposed. Simulation results using Matlab/Simulink are presented to demonstrate the robust performance during LCC inverter commutation failure to validate the operation and recovery of the hybrid system with the proposed control strategy and MMC configuration.
\end{abstract}

Index Terms - Commutation failure, hybrid HVDC, LCC, MMC, VSC, wind farm.

\section{INTRODUCTION}

Large wind farms both onshore (e.g. in China) and offshore (e.g. in Europe) have been developed with more being planned. Many of the large wind farms are located long distance away from the load centers or the available connection points. In cost-benefit terms, HVDC is likely to be preferable to HVAC technology for the main connection of large offshore wind farms when cable lengths exceed 80-120 $\mathrm{km}$. For connecting large onshore remote wind farms using overhead lines, HVDC also provides significant benefits in terms of flexible control and improved system stability, and reduced cost for transmission distance over $600 \mathrm{~km}$ [1]-[7].

It has been widely accepted that voltage source converter (VSC) based HVDC system using IGBT is the preferred DC technology for connecting wind farms due to its advantages of independent active and reactive power control, flexible AC system control and support which are particularly important for offshore wind farms [1]-[6]. A number of VSC connected offshore wind farms have already been in operation,

This work was supported in part by China Electric Power Research Institute and the State Key Laboratory of Alternate Electrical Power System with Renewable Energy, China.

R. Zeng, L. Xu, and S. Finney are with the Department of Electronic and Electrical Engineering, University of Strathclyde, Glasgow G1 1XW, UK. (email: $\quad$ rong.zeng@strath.ac.uk; lie.xu@strath.ac.uk, stephen.finney@strath.ac.uk)

L.Z. Yao is with China Electric Power Research Institute, Xiaoying Road, Beijing, 100192, China (email: yaoliangzhong@epri.sgcc.com.cn)

Y. Wang is with the State Key Laboratory of Alternate Electrical Power System with Renewable Energy Sources, North China Electric Power University, Baoding 071003, China (e-mail: yi.wang@ncepu.edu.cn) noticeably, the $400 \mathrm{MW}$ BorWin 1 [7] and the $800 \mathrm{MW}$ BorWin 2 [8]. VSC based multi-terminal HVDC systems have also been developed, e.g. the three-terminal $\pm 160 \mathrm{kV}$ Nanao project with the converters rated at $200 \mathrm{MW}, 100 \mathrm{MW}$ and 50 MW, respectively [9]. On the other hand, the conventional line commutated converter (LCC) based HVDC systems using thyristor have long been used for bulky power transmission and proven to be superior to VSC systems for high power rating in terms of cost and reliability [10]-[11]. A number of recently commissioned LCC-HVDC projects have DC voltages of up to $\pm 800 \mathrm{kV}$ and power capacity of a few $\mathrm{GW}$, e.g. the $5 \mathrm{GW}$ Yunnan-Guangdong HVDC link [12] and the 8GW Xiluodu-Zhejiang HVDC link [13]. However, LCC systems usually require relatively strong $\mathrm{AC}$ systems to operate, and thus become problematic when supplying island networks, e.g. offshore wind farms. In addition, they require larger footprint than VSCs and thus are more difficult for offshore installation.

Considering the relative advantages of the LCC and VSC systems, a hybrid HVDC system comprising a VSC converter at one terminal and a LCC at the other terminal was proposed as a cost-effective solution for wind farm power transmission [14-21]. Such configuration can also be extended to multiterminal systems by adding new VSC and/or LCC converters to existing HVDC networks. For example, there are already significant numbers of LCC-HVDC systems in operation in China and VSC converters connecting newly developed wind farms could be added with their DC sides connected to existing HVDC networks to form a large hybrid multi-terminal HVDC system. In [14]-[16], the LCC converters in the proposed systems operated as wind farm side rectifiers but such arrangements become less practical due to the various issues previously outlined. A hybrid HVDC configuration which uses a VSC to connect a wind farm and a LCC to operate as an inverter was presented and system studies under normal operation conditions were carried out [17]-[19]. However, system operation during large transients, e.g. LCC commutation failure due to disturbances in the receiving end AC grid, was not considered. Commutation failure is not a serious issue for LCC-HVDC systems due to their nature of being current source, and detailed analysis on its cause as well as control and protection strategies have been well documented [22]-[24]. In the hybrid HVDC system, however, a commutation failure in the LCC inverter is equivalent to a short circuit on the DC side, which can result in serious consequences for the VSC on the other terminal due to the existence of VSC's freewheeling diodes [25]. 
In [20], a hybrid HVDC system with a VSC rectifier and LCC inverter was presented. For this structure, the VSC controls the DC voltage and the $\mathrm{LCC}$ regulates the DC current. In order to reduce the probability of commutation failure, a voltage dependent current limit control is added to the LCC inverter. However, this method has two limitations. First, an extra fast communication between the VSC and LCC which can be expensive and causes for possible failure is needed to request the VSC to reduce DC voltage when disturbance on the LCC AC network is detected. Secondly, the DC voltage margin for conventional VSCs is fairly small since VSCs need almost constant DC voltage to ensure stable operation. Therefore, the scheme is difficult to realize in real system and is ineffective.

The objective of this paper is to investigate system behavior and operation of the hybrid HVDC system, with modular multilevel converter (MMC) based VSC rectifier connecting wind farms and LCC operating as an inverter feeding power to an AC network. LCC inverter commutation failure which results in a DC line-to-line short circuit is one of the most critical operating conditions of the hybrid HVDC system. System behavior during such an event is analyzed and control and protection strategies are investigated. Conventional MMC with half-bridge sub-modules (HBSMs) and hybrid MMC with mixed HBSMs and full-bridge submodules (FBSMs) used as the wind farm side rectifier will also be studied and corresponding control strategies are developed.

The paper is organized as follows. Section II outlines the hybrid HVDC system configuration. The detailed analysis on the behavior and operation of the hybrid HVDC system under normal and commutation failure conditions is carried out in Section III. Section IV outlines the use of a hybrid MMC with mixed HBSMs and FBSMs for the hybrid HVDC system. Simulation results are presented in Section V to demonstrate the proposed schemes and various issues are discussed in Section VI. Finally, Section VII draws the conclusions.

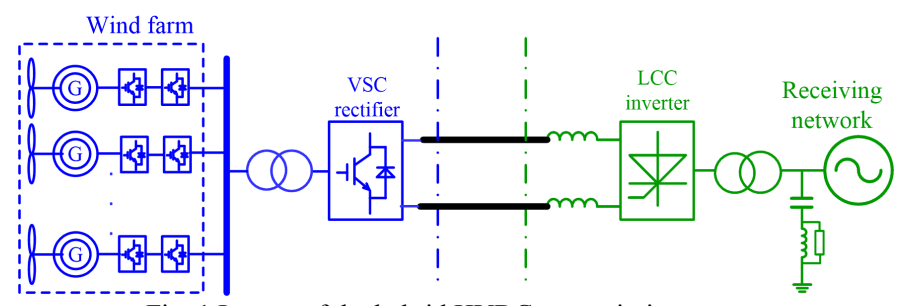

Fig. 1 Layout of the hybrid HVDC transmission system

\section{SYSTEM CONFIGURATION}

Fig. 1 shows the configuration of the hybrid HVDC transmission system. In this example a large offshore wind farm is considered though the concept is also applicable to large remote onshore wind farms connected to weak local AC grids. The wind farm side rectifier uses MMC based VSC technology as shown in Fig. 2 where each arm contains large numbers of sub-modules (SMs) [26]. On the receiving inverter terminal, LCC technology is used as schematically shown in Fig. 3. The use of MMC based VSC at the wind farm side takes its full advantages of voltage and frequency regulation for the wind farm AC network, while the use of LCC at the receiving AC grid generally provides increased converter reliability, and reduced cost and power loss compared to pure VSC designs.

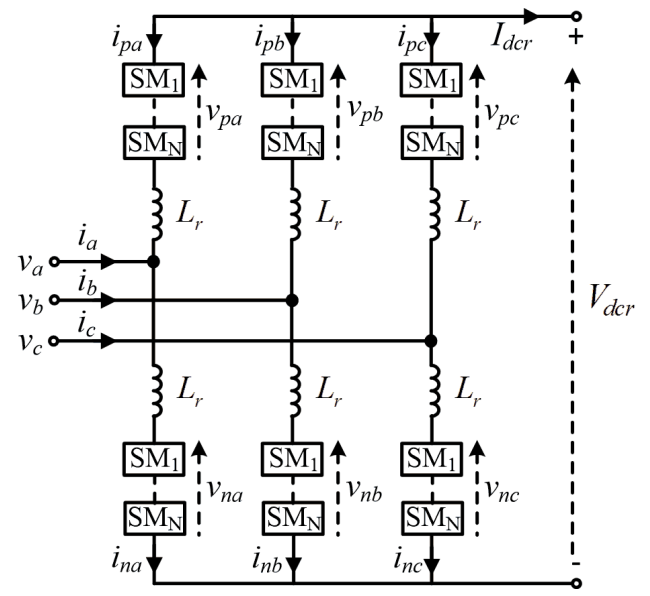

Fig. 2 Configuration of the modular multilevel converter

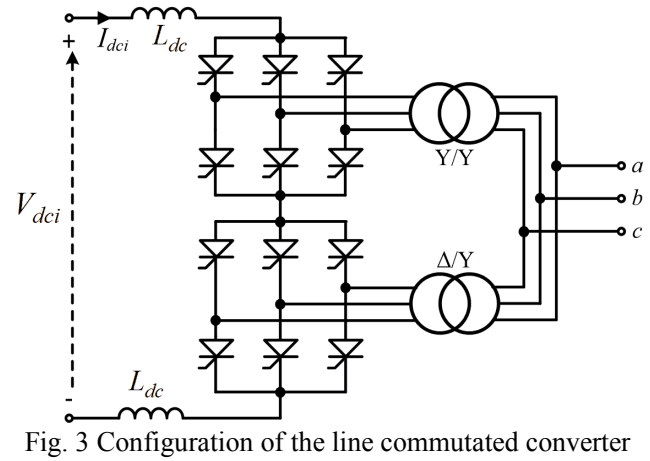

\section{HYBRID HVDC SYSTEM DURING LCC COMMUTATION FAILURE}

Normal operation of a VSC requires its DC link voltage to be maintained at a near constant value. For the hybrid HVDC system, the grid side LCC inverter is assigned to control the DC link voltage to ensure the energy absorbed by the wind farm VSC is transmitted to the AC grid. For the case of connecting an offshore wind farm, the VSC rectifier on the sending terminal regulates the $\mathrm{AC}$ voltage and frequency of the local wind farm power network to the desirable values and absorbs power generated by the wind farm. For the case of a remote onshore wind farm which is connected to a weak local AC system, the VSC controls active power flow and provides network support to the weak local AC grid, e.g. AC voltage control, network damping etc. The control and operation of the wind farm VSC [2], [3], [5], [6] and the grid side LCC [7], [8] on normal conditions have been well understood and no more description is provided here. Similarly, system control, capacitor voltage balancing algorithm and PWM modulation method for the MMC based VSC have all been well documented [26], [27], again no further detail is given here. 


\section{A. System behavior during LCC commutation failure}

LCC inverters may fail to commutate during large AC voltage drop and/or phase shift resulting from transient events on the connected AC network [22]. When commutation failure occurs the DC terminal is effectively short-circuited by the upper and lower arm thyristors on the same converter phase. For the proposed hybrid system, LCC inverter commutation failure and the effective short circuit of the DC side can result in serious consequences for the MMC based VSC on the other terminals due to the presence of their freewheeling diodes. Fig. 4 shows the equivalent circuit of the hybrid system during LCC inverter commutation failure. For simplicity, only one 6pulse LCC inverter is drawn here. For this example, when the LCC inverter fails to commutate resulting in the simultaneous conduction of $T_{3}$ and $T_{6}$ in the same phase leg, the DC side is effectively short-circuited.

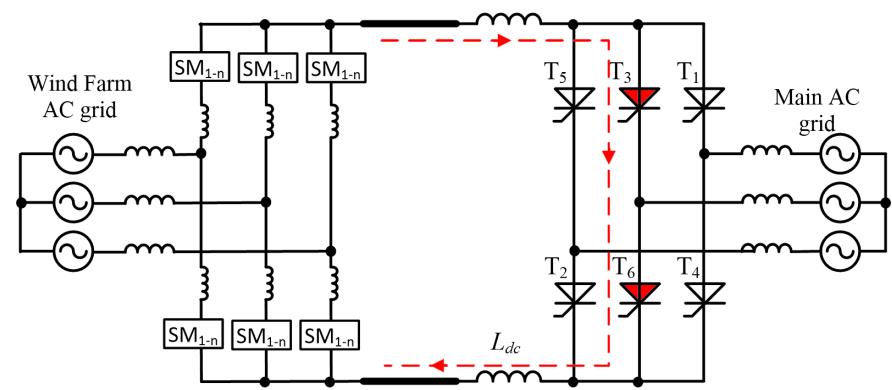

Fig. 4 Equivalent circuit of the hybrid system during inverter commutation failure

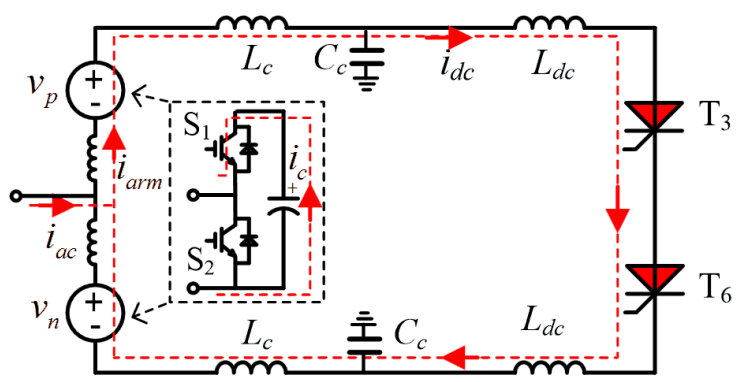

Fig. 5 Simplified equivalent circuit during the fault

To analyze the behavior of the hybrid HVDC system during commutation failure, two stages are considered.

1) Stage 1: MMC not blocked

Before the MMC is blocked, the DC cable capacitor and some of the capacitors within the SMs whose $\mathrm{S}_{1}$ is ON (named as switched-in SM capacitors, see Fig. 5) will discharge. As this stage is very short, fault current from the wind farm AC side is insignificant due to the relatively large transformer leakage impedance and thus, the fault current on the converter arm and DC side is primary due to the DC capacitor discharging. The arm current in the MMC rises quickly and its rising rate is largely determined by the arm and DC inductances. After the fault is detected by over-current on the MMC arms and/or DC side, the MMC is blocked. The system then moves to Stage 2. The simplified circuit during Stage 1 is shown in Fig. 5 where the capacitor voltages formed by the switched-in SM capacitors are shown as $v_{p}$ and $v_{n}$ for the upper and lower arms, respectively. $L_{c}$ and $C_{c}$ refer to the lumped equivalent $\mathrm{DC}$ cable inductance and capacitance, respectively.

\section{2) Stage 2: MMC blocked}

The equivalent circuit of the hybrid system after the blocking of the IGBTs in the MMC is shown in Fig. 6 where the diodes (in the example shown, $\mathrm{D}_{1}$ and $\mathrm{D}_{2}$ ) continue feeding AC fault current into $T_{3}$ and $T_{6}$. System behaviors can be different depending on the configuration of the wind farm $\mathrm{AC}$ system. If the MMC connects to a weak AC network with large onshore wind farms, the blocked MMC simply acts as an uncontrolled rectifier. High AC and DC fault current will be produced and the wind farm side $\mathrm{AC}$ voltage will also be severely affected.

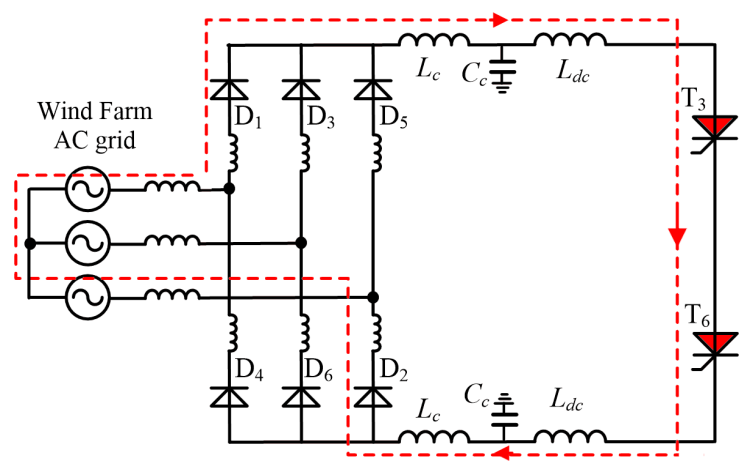

Fig. 6 Simplified equivalent circuit during commutation failure and after the blocking of the MMC.

If the wind farm is an offshore island system, the local $\mathrm{AC}$ system is usually regulated by the MMC under normal operation and its blocking could cause the AC system frequency and voltage to draft. This could potentially lead to system collapse unless the wind turbines actively taking over the $\mathrm{AC}$ voltage and frequency regulation. However, although the wind turbines can be designed to control the local AC system, they are likely to operate in current limit mode due to the rectifier action of the MMC feeding to the DC shortcircuit. The local AC system voltage will be distorted and reduced. Under this condition, the fault current will be moderate but after LCC's recovery from the commutation failure the wind farm $\mathrm{AC}$ voltage might have to be reestablished before normal power transmission can be resumed.

The potential large DC fault current flowing through the DC lines from the AC side of the MMC terminal could also make the LCC inverter difficult to recover. Thus, commutation failure can be a critical issue for the hybrid HVDC system and the conventional control and protection strategies for LCC based HVDC systems are unlikely to be suitable for the hybrid HVDC system.

\section{B. Control and protection for the hybrid HVDC system}

To enhance the operation of the hybrid HVDC under commutation failure conditions, a coordinated control scheme of the wind farm VSC rectifier and the grid side LCC inverter needs to be adopted. For the LCC, a phase-locked-loop based $\mathrm{AC}$ voltage monitor can be used to detect the $\mathrm{AC}$ voltage disturbance and a corresponding advanced firing angle, derived from the change of $\mathrm{AC}$ voltage amplitude and/or phase 
angle shift, is added to the normal firing angle to increase the commutation margin so as to avoid potential commutation failure. This scheme can reduce the commutation failure possibility for the LCC inverter [23]. However, advancing the firing angle on the LCC inverter decreases the DC link voltage. Large reduction of the DC voltage could lead to the discharging of SMs' capacitors on the rectifier MMC resulting in large DC and arm current. Consequently this could lead to the blocking of the MMC. Thus the margin of the allowed DC voltage decrease is relatively small in the hybrid HVDC system, e.g. $10 \%$, and this will limit the effectiveness of advancing the firing angle on preventing commutation failure.

Under large AC voltage disturbances, commutation failure will occur and large fault current could continuously flow through the DC line from the MMC to the LCC side. Under such conditions, the primary task is to ensure that the LCC recovers from commutation failure as soon as possible.

In order to assist fast system recovery, when commutation failure occurs which can be detected through measuring the rapid DC voltage reduction and/or fast DC current rise, a fixed firing angle of 90 degrees is applied to the LCC inverter, corresponding to zero DC voltage set point, such that once the AC voltage recovers the LCC system can regain forward voltage blocking and recover quickly. The LCC inverter's normal DC voltage control loop can then be enabled to build up the DC voltage and normal system operation can be resumed by enabling the wind farm side VSC. However, for the offshore wind farm case, if the wind farm side AC system has collapsed during commutation failure, a restarting sequence will have to be implemented before normal power transmission can be resumed.

\section{Alternative MMC TOPOLOGY FOR THE HYBRID HVDC SYSTEM}

As discussed earlier, although the LCC inverter can recover from commutation failure, the main problem is the disruption caused to the wind farm AC system potentially resulting in voltage collapse and wind farm disconnection. To tackle this issue, a hybrid MMC topology combining HBSMs and FBSMs is adopted as the wind farm side VSC, and its configuration is shown in Fig. 7 [28]. The hybrid MMC can be designed and operated similarly to a FBSM based MMC but with reduced power loss and cost. It can not only block DC side faults but also continue operating at reduced or even zero DC voltage [29]. With such advantages, the coordinated control for the hybrid HVDC system can be more flexible and the impact on the wind farm AC system during inverter commutation failure can be minimized.

As shown in Fig. 7, the hybrid MMC contains $N / 2$ HBSMs and $N / 2$ FBSMs (i.e., $F=N / 2$ ) where $N$ is the total number of $\mathrm{SMs}$ in each arm. Under normal operation, the $-V_{c}$ (where $V_{c}$ is the SM capacitor voltage) state of the FBSMs is not used. Thus, considering a maximum modulation index of 1 , the DC and peak AC phase voltages are [28]:

$$
V_{d c}=N V_{c}, \quad V_{\text {an }(\text { peak })}=1 / 2 N V_{c}=1 / 2 V_{d c}
$$

When the DC voltage drops, some of the FBSMs can be used to produce the $-V_{c}$ state. The range of the generated total arm voltage is now from $-N V_{c} / 2$ (when all the FBSMs producing $-V_{c}$ ) to $N V_{c}$ (when all the SMs producing $+V_{c}$ ). Thus, without affecting the $\mathrm{AC}$ voltage output, i.e. the peak AC phase voltage remains at $N V_{c} / 2$ as shown in (1), the maximum and minimum operational DC voltages for the hybrid MMC are given as

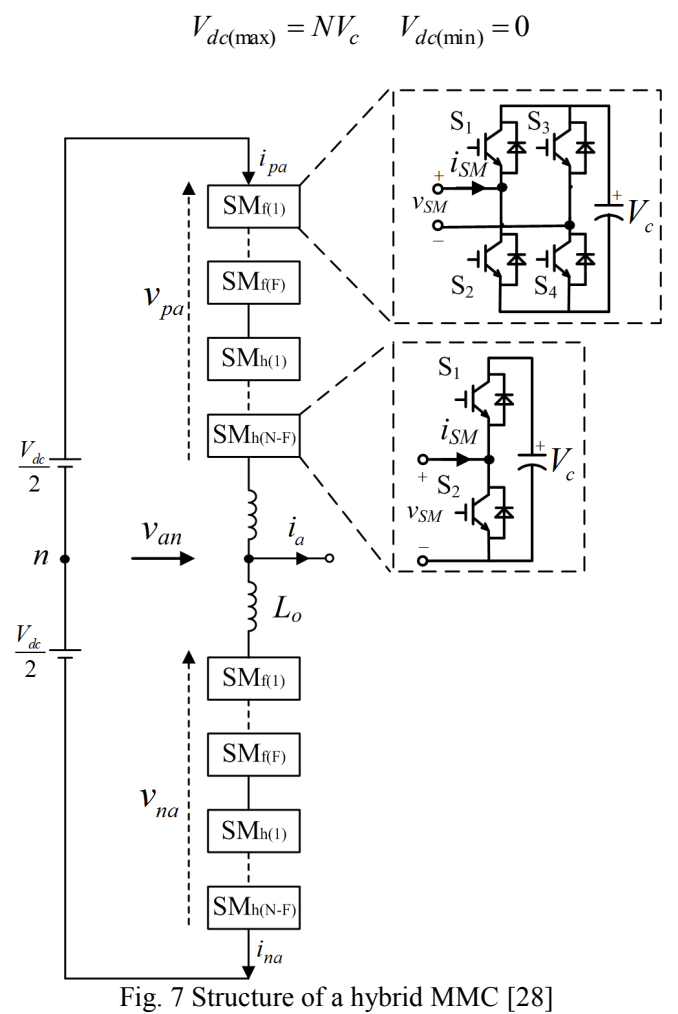

This indicates that the hybrid MMC is capable of operating at reduce $\mathrm{DC}$ voltage. The proposed coordinated control strategy for the new hybrid HVDC system thus involves the following two steps:

- When an AC voltage disturbance at the LCC side is detected, an advanced firing angle is added for the LCC to increase the commutation margin, resulting in reduced DC voltage at the inverter terminal. Consequently, the DC current rises quickly.

- The hybrid MMC rectifier at the wind farm side reduces its DC voltage output to restrain the DC current rise. In the mean time the hybrid MMC continues regulating its $\mathrm{AC}$ output to meet the operation requirement of the wind farm AC network, e.g. providing AC voltage and frequency control for offshore wind farms or regulating the active and reactive power for grid connected onshore wind farms.

A large reduction of the DC voltage reduces the maximum active power that can be transmitted by the hybrid HVDC system. For offshore wind farms, the power output from the wind turbines may have to be curtailed accordingly. A number of options can be potentially utilized for informing the wind turbines to reduce their power outputs, e.g. fast telecommunication between the wind farm VSC and individual 
wind turbines, offshore wind farm $\mathrm{AC}$ network frequency/voltage modulation etc [5].

It has to be noted that advancing the firing angle during temporary $\mathrm{AC}$ voltage dip is likely to increase the reactive current absorption by the LCC. However the disturbance caused to the AC system due to LCC's increased reactive current would be far less severe compared to the situation of commutation failure which otherwise would happen. Once the AC voltage starts to recover, the added advancing angle reduces and so as the reactive current absorption by the LCC converter.

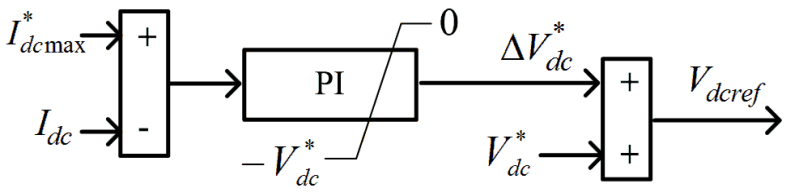

Fig. 8 Schematic diagram of the maximum DC current controller

A closed-loop maximum DC current controller is designed to limit the DC current rise by regulating the DC voltage in the hybrid MMC on the wind farm side and its schematic diagram is shown in Fig. 8. $I_{d c \max }^{*}$ is the maximum DC current reference during fault, $I_{d c}$ is the measured DC current, $V_{d c}^{*}$ is the rated DC voltage and $V_{\text {dcref }}$ is the DC voltage reference for the MMC. As seen in Fig. 8, the output of the PI controller is limited between 0 and $-V_{d c}^{*}$. Under normal operation, since the actual DC current is less than $I_{d c \max }^{*}$, the input to the PI controller is positive and the controller produces a maximum output of 0 . As $\Delta V_{d c}^{*}=0, V_{d c r e f}$. equals to the rated DC voltage of $V_{d c}^{*}$. Thus, this control loop has no effect and the MMC produces rated DC voltage output. However, when DC over-current occurs due to reduced DC voltage on the LCC inverter side, i.e. $I_{d c}>I_{d c \max }^{*}$, the PI controller will produce negative output $\left(\Delta V_{d c}^{*}<0\right)$. Thus, $V_{d c r e f}<V_{d c}^{*}$ and the MMC output DC voltage will then be reduced automatically (as $V_{\text {dcref }}$ is reduced) so as to limit the DC current to the preset maximum value. It has to be noted that care must be taken to ensure the PI controller does not suffer from integrator windup. In the simulation studies below, anti-windup mechanism using clamping which stops integration when the PI output exceeds the limit was implemented [30].

Under such operating conditions, the voltages on the AC, the upper and lower arms (taking phase a as an example), and the $\mathrm{DC}$ side are given as

$$
\begin{gathered}
v_{p a}=\frac{1}{2} V_{d c r e f}-V_{a} \sin (\omega t), \quad v_{n a}=\frac{1}{2} V_{d c r e f}+V_{a} \sin (\omega t) \\
v_{a n}=\frac{v_{n a}-v_{p a}}{2}=V_{a} \sin (\omega t) \\
V_{d c}=v_{p a}+v_{n a}=V_{d c r e f}
\end{gathered}
$$

where $V_{a}$ refers to the required peak $\mathrm{AC}$ phase voltage from the MMC, $v_{p a}$ and $v_{n a}$ represent the upper and lower arm voltages shown in Fig. 7, respectively.
As can be seen from (3)-(5), the hybrid MMC output DC voltage drops according to $V_{\text {dcref }}$ but the converter continues controlling the wind farm AC voltage as $v_{a n}$ is not affected. Obviously the hybrid MMC is not able to transmit active power during zero DC voltage and therefore, wind farm deloading process as previously described will need to be implemented. As the DC fault current is limited to $I_{d c \max }^{*}$, e.g. 1.3 p.u., and the DC voltage is reduced, the LCC inverter can be prevented from commutation failure or can recover from commutation failure quickly. After the recovery of the inverter side AC voltage, the LCC returns to the normal DC voltage control by increasing its firing angle. Consequently, the DC voltage rises and the DC current decreases. The DC voltage loop at the hybrid MMC terminal ceases action due to the reduced DC current and switches back to normal active power control. This control method can also be applied to hybrid multi-terminal HVDC systems having multiple VSCs as each VSC is able to control its DC current to the preset maximum value.

\section{Simulation STUdies}

To verify the above analysis and the proposed control strategy, a two-terminal hybrid HVDC system model configured as symmetrical monopole with one MMC based rectifier terminal and one LCC inverter terminal is developed using Matlab/Simulink and is shown in Fig. 9. The rectifier MMC adopts two configurations, i.e. conventional HBSM based MMC and the hybrid MMC illustrated in section IV. The wind farm is considered as being connected to a conventional weak $\mathrm{AC}$ network and is represented by a simplified AC system model using a fixed voltage source and an impedance. The LCC uses the 12-pulse three-phase bridge structure shown in Fig. 3. Average MMC models with controllable voltage and current sources are used, and additional semiconductor devices are added to ensure that the model accurately replicates all possible current paths in a real converter during DC faults [31]. The main parameters of the hybrid HVDC system are listed in Table I.

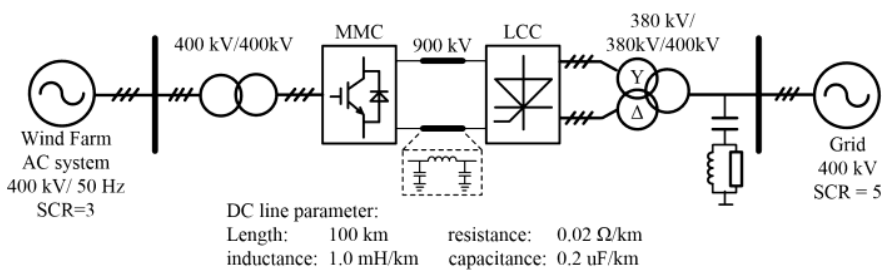

Fig. 9 Structure of the simulated hybrid HVDC configuration

TABLE I PARAMETERS OF THE SIMULATION HYBRID HVDC SYSTEM

\begin{tabular}{c|c}
\hline Item & Values \\
\hline System rated power & $1000 \mathrm{MW}$ \\
\hline DC rated voltage & $\pm 450 \mathrm{kV}$ \\
\hline Wind farm AC network & $400 \mathrm{kV} / 50 \mathrm{~Hz} / \mathrm{SCR}=3$ \\
\hline Main AC grid network & $400 \mathrm{kV} / 50 \mathrm{~Hz} / \mathrm{SCR}=5$ \\
\hline LCC DC smooth reactor & $0.5 \mathrm{H}$ \\
\hline MMC arm reactor & $60 \mathrm{mH}$ \\
\hline
\end{tabular}



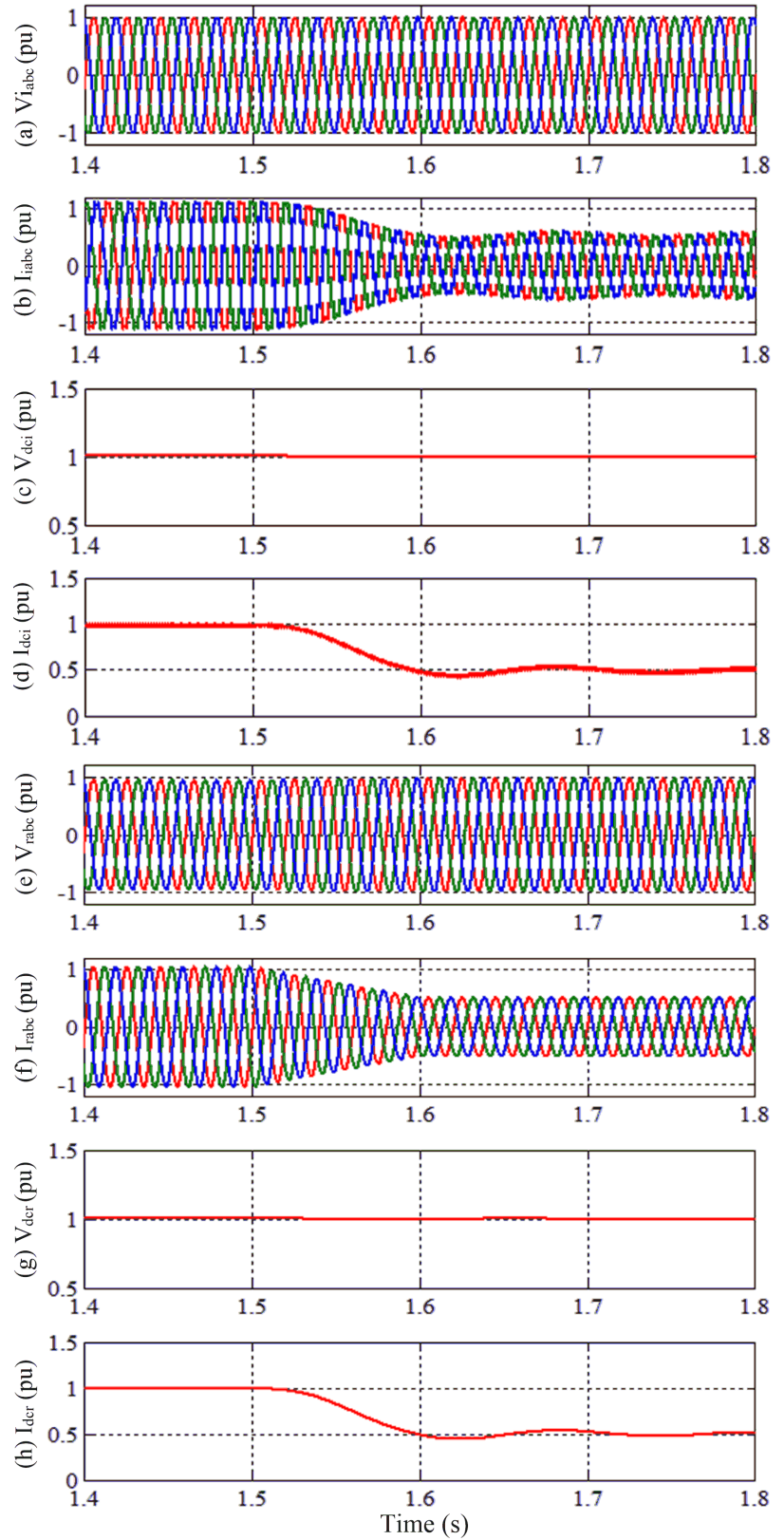

Fig. 10 Normal operation of the hybrid HVDC system, (a) AC voltage at the LCC; (b) AC current at the LCC; (c) DC voltage at the LCC; (d) DC current at the LCC; (e) AC voltage at the MMC; (e) AC current at the MMC; (g) DC voltage at the MMC; (h) DC current at the MMC.

Simulation studies are carried out to illustrate the operation characteristics of the hybrid HVDC system under normal and fault conditions. Fig. 10 shows the results during normal operation. The LCC controls the DC voltage to the rated value, and the wind farm MMC regulates the active and reactive power on the wind farm $\mathrm{AC}$ grid. At $1.5 \mathrm{~s}$, the transmitted power is ramped down from 1.0 p.u. to 0.5 p.u.. As can be seen that the DC voltage is well controlled during power variation and the operation of the system is satisfactory.

At $1.5 \mathrm{~s}$, a $60 \mathrm{~ms} \mathrm{AC}$ fault happens at the receiving power grid, resulting in a drop of three-phase $\mathrm{AC}$ voltage from 1.0 p.u. to around 0.5 p.u.. The response of the conventional halfbridge MMC and LCC without using firing angle advancing control is shown in Fig. 11. When the fault occurs, the grid
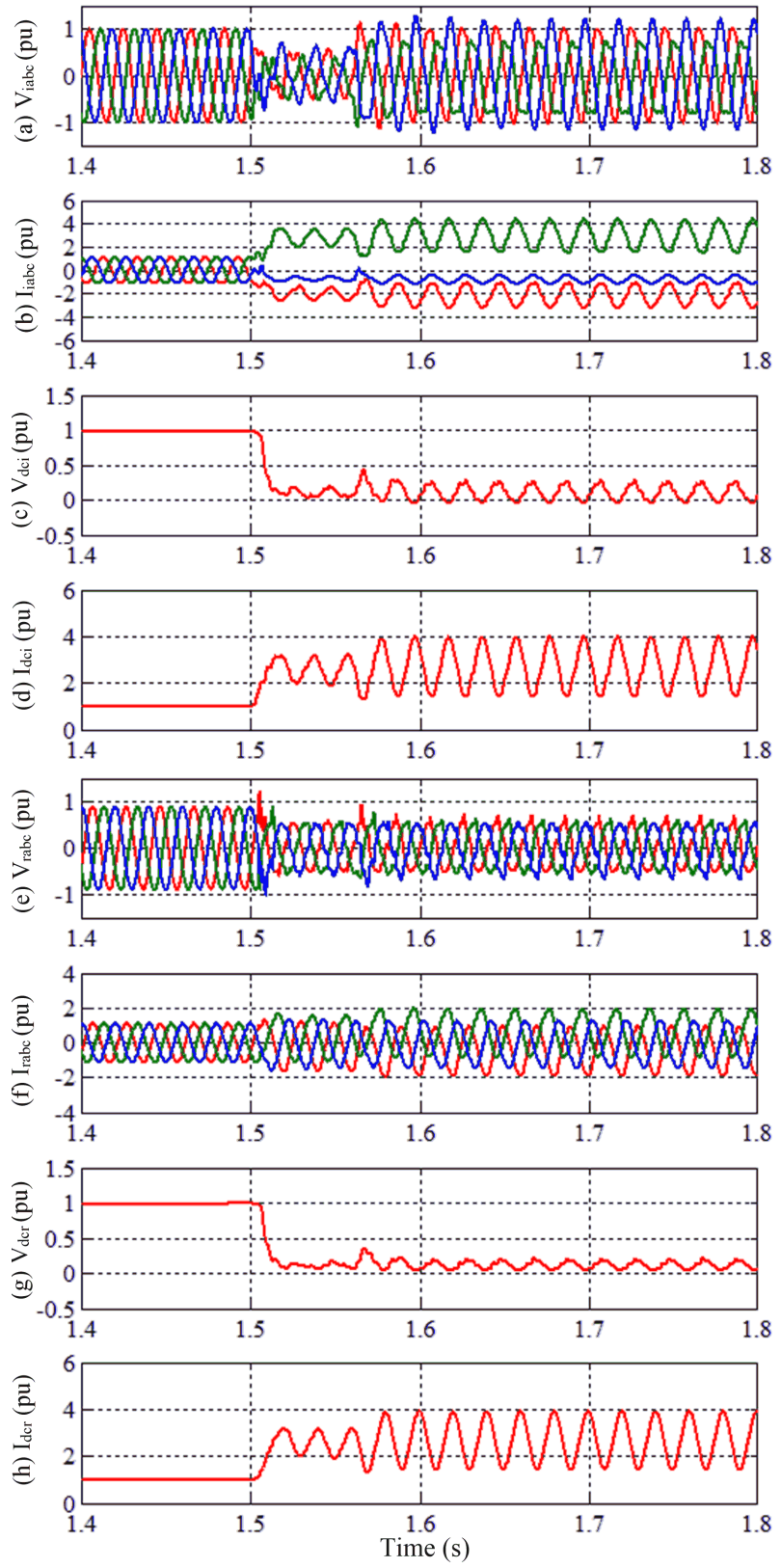

Fig. 11 Hybrid HVDC using conventional MMC and LCC without the firing angle advancing control during an AC fault.

side LCC fails commutation which results in the short-circuit of the DC link. The DC voltage is reduced to near zero and the DC current rises immediately. The MMC quickly experiences over-current and is subsequently blocked. At this point, the MMC is equivalent to a three-phase uncontrolled diode rectifier. The DC current increases to around 3 p.u. and also contains significant oscillations. The AC current at the wind farm MMC also increases although due to the existing impedance in the wind farm $\mathrm{AC}$ network and the existence of the transformer and arm impedances, the $\mathrm{AC}$ fault current is limited to less than 2 p.u.. The AC terminal voltage is reduced and becomes distorted due to the distorted AC current. In addition, as can be seen, after the clearance of the inverter $\mathrm{AC}$ fault and the recovery of the AC voltage, the LCC fails to recover from the commutation failure due to the large DC fault current. 

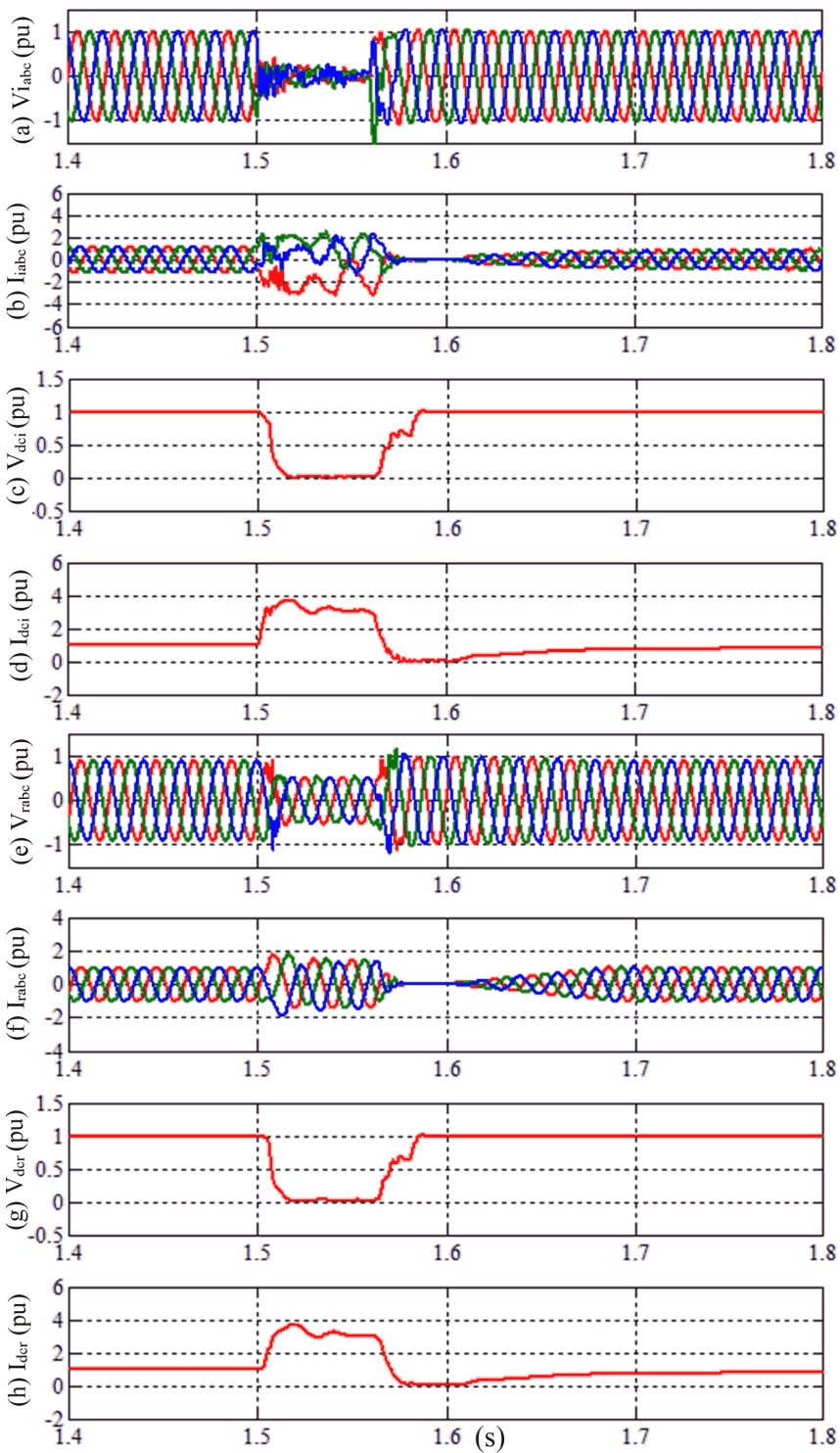

Fig. 12 Hybrid HVDC using conventional MMC and LCC with firing angle advancing during $\mathrm{AC}$ fault.

Fig. 12 shows the behavior of the hybrid HVDC system with the firing angle advancing control under a more severe AC fault which reduces the $\mathrm{AC}$ voltage to 0.2 p.u.. Commutation failure occurs after the $\mathrm{AC}$ fault, and the $\mathrm{MMC}$ on the wind farm side has to be blocked and an uncontrolled DC current (approximately 3.2 p.u.) flows through the DC line during the fault period. The firing angle of the LCC is advanced to 90 degrees after the detection of the commutation failure, such that the LCC can recover quickly after the AC fault clearance and the disturbance caused to the wind farm side AC system is less severe compared to those shown in Fig. 11. After the LCC recovers from commutation failure and regains DC voltage control, the power export by the MMC is ramped up and system goes back to normal operation.

Fig. 13 shows the results of the hybrid HVDC system using the hybrid MMC configuration. Under the same severe AC fault at $1.5 \mathrm{~s}$, the firing angle of the LCC is quickly advanced, which results in the reduction of the DC voltage at the LCC inverter side as can be seen from Fig. 13 (c). Consequently,
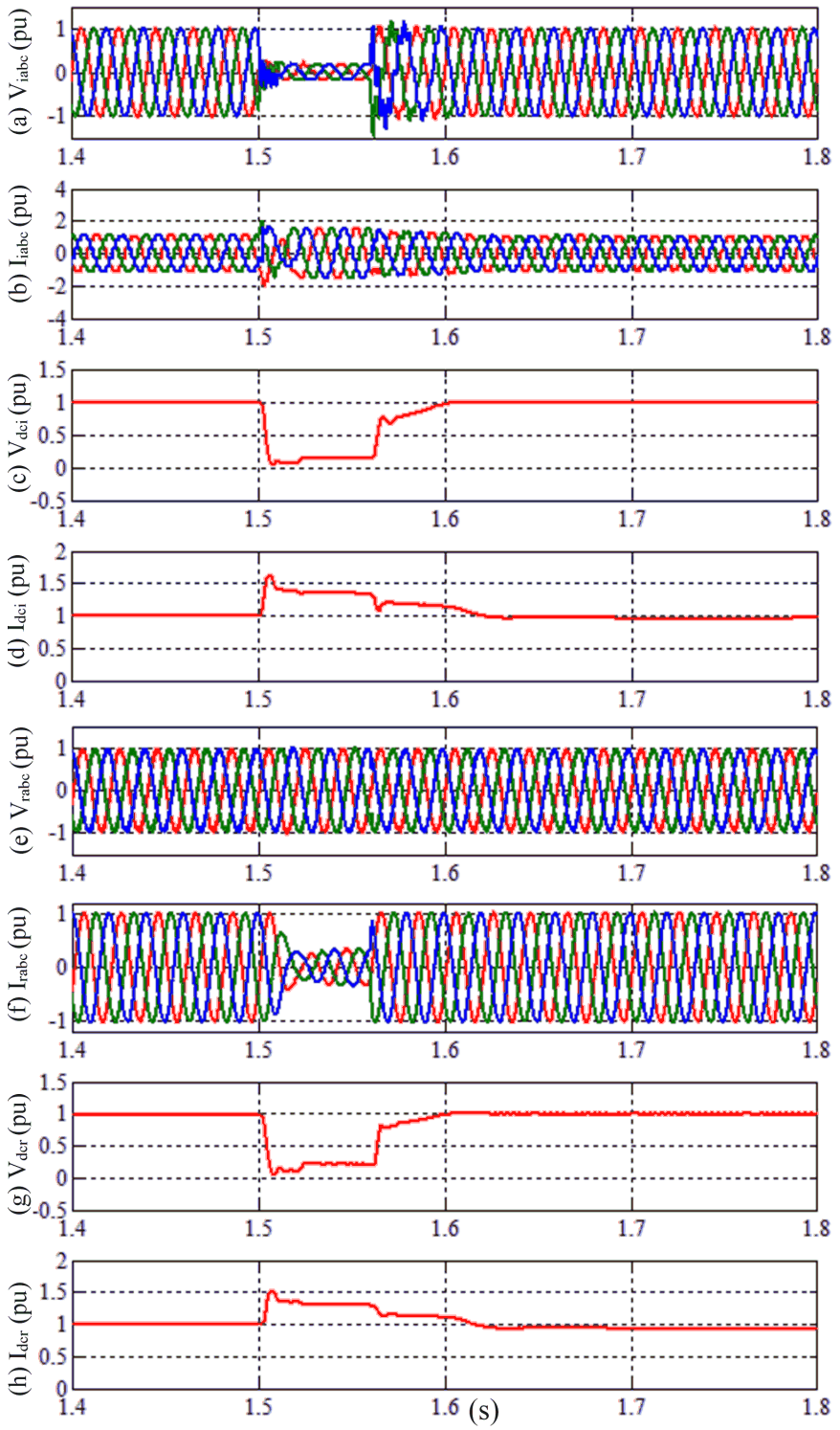

Fig. 13 Hybrid MMC rectifier and LCC inverter during AC fault

the DC current rises and hits the 1.3 p.u. limit set by the maximum DC current controller of the hybrid MMC on the rectifier side, shown in Fig. 13(h). Thus, the DC voltage of the hybrid MMC decreases automatically to restrain the DC current to around 1.3 p.u.. The AC current on the wind farm hybrid MMC shown in Fig. 13 (f) reduces accordingly due to the reduction of active power transfer but remains being fully controlled.

Due to the controlled reduction of the DC voltage and current, commutation failure is being prevented in this study. After the fault clearance, the AC voltage at the LCC inverter terminal recovers quickly and thus, the inverter DC voltage rises rapidly. However, on the rectifier side, the DC voltage remains low due to the action of the maximum DC current controller of the hybrid MMC (i.e. $V_{d c r e f}<V_{d c}^{*}$ ) and thus, the DC current drops. Consequently, the input to the PI controller of the maximum DC current controller shown in Fig. 8 becomes positive and its output quickly reaches the upper limit of 0 . Thus, $V_{d c r e f}$ quickly moves back to $V_{d c}^{*}$ and the system 
gradually returns to normal operation. The wind farm side hybrid MMC returns to power control and the system quickly goes back to normal operation. Throughout the whole process, the effect on the wind farm AC network is only the reduction of active power transmission. The simulation results verify the excellent fault ride-through performance of the hybrid HVDC with the hybrid MMC on the wind farm side and the proposed control strategy.

\section{DISCUSSIONS}

The hybrid HVDC system using LCC and hybrid MMC combining HBSMs and FBSMs provides flexible control during large $\mathrm{AC}$ voltage dips and commutation failure can either be prevented or its impact can be minimized. In addition, both the hybrid MMC [29] and LCC used in the proposed hybrid HVDC system are naturally DC fault tolerant. Therefore, compared to conventional HBSM MMC based VSC-HVDC systems which can cause large disruption during a DC fault especially for multi-terminal HVDC networks, the hybrid HVDC can safely ride-through a transient DC fault without additional protection equipment, e.g. fast acting DC circuit breakers. This could bring significant technical and cost benefits for the hybrid HVDC system.

As estimated in [28], the hybrid MMC has $25 \%$ higher converter power loss than a HBSM based MMC. The power loss for a typical LCC converter is around $0.6 \%$ [32] while a typical MMC has power loss of around 1.0\% [33]. Therefore, the total converter power loss of the proposed hybrid HVDC system is likely to be slightly lower than a VSC-HVDC system using conventional HBSM based MMCs. As the hybrid MMC uses $50 \%$ more semiconductor devices than the conventional MMC the capital cost for the rectifier hybrid MMC will be higher. However, the cost for a LCC converter can be lower than a MMC at very high power level although the relative cost will be case dependent and can vary significantly for different applications taking into account the location (e.g., offshore, onshore), connected AC system condition, etc. On the other hand, compared to the hybrid HVDC system, conventional HBSM based VSC-HVDC systems can be more flexible in terms of operating during receiving end $\mathrm{AC}$ system transient and have the ability to provide faster reactive power control and network support to the connected AC network. In addition, a point-to-point VSC-LCC hybrid scheme does not have bidirectional power capability and additional auxiliary power supply might be needed to supply the wind turbines when they are not in operation. Nevertheless, the proposed hybrid HVDC system can potentially provide an alternative solution for the future expansion of large HVDC networks.

\section{CONCLUSIONS}

Hybrid HVDC transmission system using MMC rectifier and LCC inverter for wind farm integration is studied in this paper. Impacts of commutation failure on the hybrid HVDC system are analysed and relevant control and protection strategies are investigated. LCC commutation failure potentially results in large fault current on both the MMC and DC side and causes large disturbance to the sending end wind farm AC system. System recovery after the clearance of the LCC AC grid fault could also be jeopardized. Advancing the LCC firing angle during fault helps the hybrid HVDC system to recover after fault clearance, though the large uncontrolled DC current and disturbance to the wind farm AC system still exist. A hybrid MMC topology combining half-bridge and fullbridge sub-modules which are capable of operating at reduced DC voltage is then adopted and a coordinated control strategy for the hybrid HVDC system is proposed. Simulation results demonstrate the advantages of this scheme in terms of response and protection during the receiving end $\mathrm{AC}$ grid fault and quick recovery after fault clearance.

\section{REFERENCES}

[1] N. Flourentzou, V. G. Agelidis, and G. D. Demetriades, "VSCBased HVDC Power Transmission Systems: An Overview," IEEE Trans. Ind. Appl., vol. 24, pp. 592-602, 2009.

[2] L. Xu, L. Yao, and C. Sasse, "Grid Integration of Large DFIGBased Wind Farms Using VSC Transmission," IEEE Trans. Power Sys., vol. 22, pp. 976-984, 2007.

[3] L. Xu, B. W. Williams, and L. Z. Yao, "Multi-terminal DC transmission systems for connecting large offshore wind farms," in Proc. IEEE PES General Meeting, 2008, pp. 1-7.

[4] Y. Jin, J. E. Fletcher, and J. O'Reilly, "Multiterminal DC Wind Farm Collection Grid Internal Fault Analysis and Protection Design," IEEE Trans. Power Del, vol. 25, pp. 2308-2318, 2010.

[5] L. Xu and L. Z. Yao, "DC voltage control and power dispatch of a multi-terminal HVDC system for integrating large offshore wind farms," IET Renew. Power Gen., vol. 5, pp. 223-233, 2011.

[6] J. Liang, T. Jing, O. Gomis-Bellmunt, J. Ekanayake, and N. Jenkins, "Operation and Control of Multiterminal HVDC Transmission for Offshore Wind Farms," IEEE Trans. Power Del, vol. 26, pp. 2596-2604, 2011.

[7] http://new.abb.com/systems/hvdc/references/borwin1, accessed on 11 Feb. 2015.

[8] http://www.siemens.com/press/en/feature/2013/energy/2013-08-xwin.php, accessed on 11 Feb. 2015.

[9] X. Li, Z. Yuan, J. Fu, Y. wang, T. Liu, and Z. Zhu, "Nanao multiterminal VSC-HVDC project for integrating large-scale wind generation", in Proc. IEEE PES General Meeting, 2014, pp. 1-8.

[10] S. Foster, L. Xu, and B. Fox, "Control of an LCC HVDC system for connecting large offshore wind farms with special consideration of grid fault," in Proc. IEEE PES General Meeting, 2008, pp. 1-8.

[11] B. Serhiy, G. Asher, R. S. Li, J. Clare, and L. Z. Yao, "Large Offshore DFIG-Based Wind Farm With Line-Commutated HVDC Connection to the Main Grid: Engineering Studies," IEEE Trans. Energy Conv., vol. 23, pp. 119-127, 2008.

[12] H. Cao, "The System Tests of Yunnan-Guangdong $\pm 800 \mathrm{kV}$ DC Transmission Project", Southern Power System technology, vol. 4, no. 2, pp. 7-14, 2010.

[13] http://www.cepri.com.cn/aid/details_72_273.html, accessed on 11 Feb. 2015.

[14] X. Chen, H. S. Sun, J. Y. Wen, W. J. Lee, X. F. Yuan, N. H. Li, and L. Z. Yao, "Integrating Wind Farm to the Grid Using Hybrid Multiterminal HVDC Technology," IEEE Trans. Ind. Appl., vol. 47, pp. 965-972, 2011.

[15] Z. Zhang, Z. Xu, Y. Xue, and G. Tang, "DC-Side Harmonic Currents Calculation and DC-Loop Resonance Analysis for an LCC-MMC Hybrid HVDC Transmission System," IEEE Trans. Power Del., vol. 30, pp. 642-651, 2014.

[16] Y. Lee, S. Cui, S. Kim, and S.K. Sul, "Control of hybrid HVDC transmission system with LCC and FB-MMC," in Proc. IEEE ECCE, 2014, pp. 475-482, Sept. 2014.

[17] C. H. Li, P. Zhan, J. Y. Wen, M. Q. Yao, N. H. Li, and W. J. Lee, "Offshore Wind Farm Integration and Frequency Support Control 
Utilizing Hybrid Multiterminal HVDC Transmission," IEEE Trans. Ind. Appl., vol. 50, pp. 2788-2797, 2014.

[18] R. E. Torres-Olguin, M. Molinas, and T. Undeland, "Offshore Wind Farm Grid Integration by VSC Technology With LCC-Based HVDC Transmission," IEEE Trans. Sus. Energy, vol. 3, pp. 899907, 2012

[19] W. L. Pan, Y. Chang, and H. R. Chen, "Hybrid Multi-terminal HVDC System for Large Scale Wind Power," in Proc. IEEE PES Power Sys. Conf. and Expo., 2006, pp. 755-759.

[20] W. J. Liu, C. Y. Zhao, and C. Y. Guo, "The control strategy for Hybrid HVDC using voltage margin control and voltage dependent current order limiter control," in Proc. 2nd IET Ren. Power Gen. Conf. (RPG 2013), 2013, pp. 1-4.

[21] P. Manohar, V. Kelamane, D. Kaushik, and W. Ahmed, "Improved controls for LCC-VSC hybrid HVDC system," in Proc. Circuits, Controls and Communications (CCUBE), 2013, pp. 1-5.

[22] L. D. Zhang and L. Dofnas, "A novel method to mitigate commutation failures in HVDC systems," in Proc. Power Sys. Tech., 2002, vol. 1, pp. 51-56.

[23] A. Hansen and H. Havemann, "Decreasing the commutation failure frequency in HVDC transmission systems," IEEE Trans. Power Del., vol. 15, pp. 1022-1026, 2000.

[24] C. V. Thio, J. B. Davies, and K. L. Kent, "Commutation failures in HVDC transmission systems," IEEE Trans. Power. Del., vol. 11, pp. 946-957, 1996.

[25] J. Rafferty, L Xu, and D.J. Morrow, "Analysis of VSC-based HighVoltage Direct Current under DC Line-to-earth Fault", IET Power Electron, vol. 8, pp. 428-438, 2015

[26] Q. R. Tu, Z. Xu, and L. Xu, "Reduced Switching-Frequency Modulation and Circulating Current Suppression for Modular Multilevel Converters," IEEE Trans. Power Del., vol. 26, pp. 20092017, 2011.

[27] M. Saeedifard and R. Iravani, "Dynamic performance of a modular multilevel back-to-back HVDC system," IEEE Trans. Power Del., vol. 25, pp. 2903-2912, 2010

[28] R. Zeng, L. Xu, L. Z. Yao, and B. W. Williams, "Design and Operation of a Hybrid Modular Multilevel Converter," IEEE Trans. Power Electron., vol. 30, pp. 1137-1146, March 2015.

[29] R. Zeng, L. Xu, L. Yao, and D. J. Morrow "Pre-charging and DC Fault Ride-Through of Hybrid MMC Based HVDC Systems", IEEE Trans. Power Del., vol. 30, pp. 1298-1306, 2015.

[30] Simulink help, available online: http://www.mathworks.com/help /releases/R2013a/simulink/slref/pidcontroller.html

[31] R. Zeng, L. Xu, L. Yao, " DC/DC Converters Based on Hybrid MMC for HVDC Grid Interconnection", in proc. $11^{\text {th }}$ IET AC/DC Power Trans. Conf., Feb. 2015.

[32] Online: http://www.abb.co.uk/industries/, accessed on $10^{\text {th }}$ April 2015

[33] "HVDC Light - It's time to connect", available online: http://www05.abb.com/global/scot/scot221.nsf/, accessed on 10 April 2015.

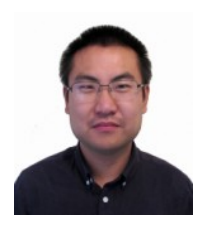

Rong Zeng (S'10) received the B.Sc. degree and M.Sc degree in electrical engineering from Hunan University, Changsha, China in 2008 and Zhejiang University, Hangzhou, China, in 2011, respectively.

Since 2012, he has been working toward the Ph.D. degree in the Department of Electronic \& Electrical Engineering, University of Strathclyde, Glasgow, UK. His research interest includes high power converters for HVDC application and grid integration of renewable energy systems.

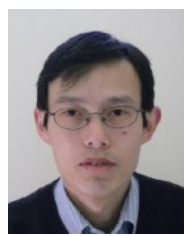

Lie Xu (M'03-SM'06) received the B.Sc. degree in Mechatronics from Zhejiang University, Hangzhou, China, in 1993, and the Ph.D. degree in Electrical Engineering from the University of Sheffield, Sheffield, UK, in 2000.

$\mathrm{He}$ is currently with the Department of Electronic \& Electrical Engineering, University of Strathclyde, Glasgow, UK. He previously worked in Queen's University of Belfast and ALSTOM T\&D, Stafford, UK. His research interests include power electronics, wind energy generation and grid integration, and application of power electronics to power systems.

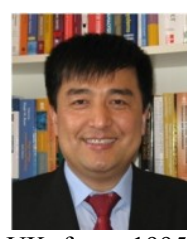

Liangzhong Yao (SM'12) received the M.Sc. degree in 1989 and Ph.D. degree in 1993 all in electrical power engineering from Tsinghua University, Beijing, China.

He joined the State Grid of China in 2011 and is now the Vice President of China Electric Power Research Institute (CEPRI). He was a post doctoral research associate at University of Manchester (former UMIST), UK from 1995 to 1999 , a senior power system analyst in the network consulting department at ABB UK Ltd from 1999 to 2004, and the department manager for network solutions, renewables \& smart grids technologies at ALSTOM Grid Research \& Technology Centre, Stafford, UK from 2004 to 2011. Dr Yao is a Chartered Engineer, a Fellow of the IET, and a member of the CIGRE. He is also a guest Professor at Shanghai Jiao Tong University, Shanghai, and Sichuan University, Chengdu, China.

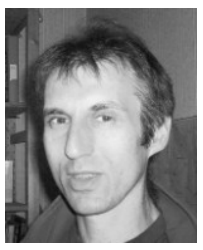

Stephen J. Finney obtained an M.Eng. degree in Electrical and Electronic Engineering from Loughborough University of Technology, UK in 1988 and Ph.D. degree in Electrical Engineering from HeriotWatt University, Edinburgh, UK in 1994.

From 1994 to 2005 he was a member of academic staff at Heriot-Watt University. In 2005 he moved to the University of Strathclyde where he is currently Professor with the Institute of Energy and Environment, specialising in power electronic systems. His research interests include the power electronics for high power applications and the use of power electronics for power transmission and distribution. He has published extensively in IEEE and IEE journals.

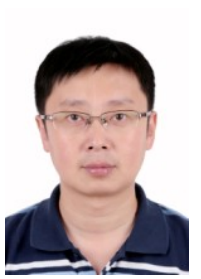

Yi Wang (S'04-M'06) received the B.Sc. and Ph.D. degree in electrical engineering from North China Electric Power University, Baoding, China, in 1999 and 2005, respectively.

Currently, he is a Professor in the School of Electrical and Electronic Engineering, North China Electric Power University. He was a Postdoctoral Research Fellow at Queen's University, Belfast, U.K., from 2006 to 2007, and with the University of Strathclyde, Glasgow, U.K., from 2007 to 2009. His research interests are power electronics applications in power system, including wind power integration, VSC-HVDC, and DC grid. 